\title{
Effect of genetic European taurine ancestry on milk yield of Ankole-Holstein crossbred dairy cattle in mixed smallholders system of Burundi highlands
}

\author{
J. Manirakiza*, G. Hatungumukama*, S. Thévenon ${ }^{\dagger}$, M. Gautier ${ }^{\ddagger \S}$, B. Besbes ${ }^{\oplus}$, L. Flori ${ }^{\dagger^{* *}+\dagger}$ and \\ J. Detilleux ${ }^{+*}$ \\ *Faculté d'Agronomie et de Bio-Ingénierie, Université du Burundi, B.P. 2940, Bujumbura, Burundi. †UMR INTERTRYP, CIRAD, F34398 \\ Montpellier, France. ${ }^{\ddagger}$ UMR CBGP (INRA/CIRAD/IRD/Supagro), INRA, F34988 Montferrier-sur-Lez, France. ${ }^{\S}$ IBC, Institut de Biologie \\ Computationnelle, 34095 Montpellier, France. "Animal Production and Health Division, FAO, Viale delle Terme di Caracalla, 00153 Rome, \\ Italy. ${ }^{*}$ AgroParisTech, GABI, INRA, Université Paris-Saclay, 78350 Jouy-en-Josas, France. ${ }^{\dagger}$ Montpellier SupAgro, SELMET, CIRAD, INRA, \\ 34398 Montpellier, France. ${ }^{*}$ FARAH, Productions Durables, Université de Liège, 4000 Liège, Belgium.
}

\section{Summary}

\section{Introduction}

In Burundi, growth and high density of human population are responsible for the reduction in pasture land. This ongoing reduction restricts animal mobility and elicits a decrease in the number of cows per households. The traditional extensive agro-pastoral system (TEAP), which

Address for correspondence

J. Detilleux, University of Liege, Quartier Vallée 2, Avenue de Cureghem, 6, 4000 Liège, Belgium.

E-mail: jdetilleux@ulg.ac.be

and

G. Hatungumukama, Faculté d'Agronomie et de Bio-Ingénierie, Université du Burundi, B.P. 2940, Bujumbura, Burundi.

E-mail: hatungumukama@yahoo.com

Accepted for publication 16 May 2017
Different breeding systems associated with specific bovine genetic resources have coexisted in Burundi. To prepare for the development of a national action plan for the improvement of bovine genetic resources in Burundi, we aimed at performing genetic characterization of Ankole and Ankole $\times$ European crossbred individuals and assessing the effect of European ancestry on milk productivity of cows kept under the mixed crops livestock system. To that end, we genotyped 37 Ankole and 138 crossbred individuals on 42636 SNPs and combined these genotypes with those from 21 cattle breeds, representative of the bovine genetic diversity. We also measured milk yield not suckled and estimated suckled milk. Given the results, we confirmed the indicine $\times$ African taurine admixed origin of the Ankole in Burundi and showed that crossbred individuals present a high proportion of European ancestry (i.e. $57 \%$ on average). As the proportion of European ancestry increased, milk yield increased by $0.03 \pm 0.01 \mathrm{l} /$ day, at a lower extent than expected. We also observed that breeders were unable to correctly evaluate the European proportion in their livestock. Our results may provide useful information for objective dairy breeding in Burundi. As an example, an ex-situ conservation program of Ankole within the framework of value chains is proposed as an accompanying strategy to improve the sustainability of the crossbreeding program.

Keywords crossbreeding, daily milk yield, ex-situ conservation, genetic diversity, mixed crops-livestock system, smallholdings consists of letting animals graze from morning to evening and come back to night shelters, is gradually being replaced by the mixed-crops livestock system (MCLS), in which cows are mainly confined during the day and fed with forage and crop residues. The MCLS thus has become the most frequent system in smallholdings (with one to three head per farmer) commonly found in Burundi. Indeed, it is less expensive than TEAPs in terms of space and less expensive in terms of investment than is the dairy intensive system, which is developing around major cities, especially around Gitega and Bujumbura, where the demand for fresh milk is high. It also has the advantage of producing high quantities of manure used for crop fertilization, which is of interest in Burundi where lands are overexploited. At the global level, this system is also recognized to be the most resilient to climate extremes, to improve nutrient recycling and to increase income diversity (Weindl et al. 2015). 
Local breeds, such as Ankole, are characterized by poor dairy potential but valuable adaptation to harsh environments (e.g., Wurzinger et al. 2006). In contrast, dairy-type European taurine (EUT), such as Holstein, are characterized by high milk potential and poor adaptation to harsh tropical environments (e.g. Tadesse \& Dessie 2003). In the 1993 post-conflict context of Burundi, the government, with the support of technical and financial partners, promoted the importation of Holstein crossbred cows from Uganda to be given to rural poor smallholders. Indeed, it was believed these crossbred cows would be well adapted to MCLS and produce more than would pure local breeds raised in the same breeding system. As a consequence, the cattle population in Burundi is now mainly a mix of crossbred cows. However, thus far no study has reported on the use of genetic markers to assess the importance of EUT cattle introgression in Burundi cattle. It is also unknown by how much the introduction of EUT crossbred individuals has been improving milk productivity in MCLS. Indeed, crossbreeding programs in the tropics face several challenges that may limit the advantages of heterosis and breed complementarity and jeopardize the sustainability of the system (Galukande et al. 2013; Leroy et al. 2015).

This preliminary study aimed to (i) genetically characterize the Ankole breed from Burundi and the crossbred populations and (ii) identify the genetic contribution of EUT ancestry in crossbred cows kept under the MCLS of Burundi and its effect on daily milk yield (DMY). Because nongenetic factors, such as parity, stage of lactation, climate, cattle management and feeding, have been reported to affect milk production (e.g. Hatungumukama et al. 2008), they were taken into account in the estimation of the effect of EUT ancestry on milk yield.

\section{Materials and methods}

\section{Population and study area}

The study was conducted in the highland natural region of Crete Congo Nil (1700-2500 m in altitude) in the province of Bururi, located in the southern part of Burundi. This region has the highest annual rainfall (1500-2000 mm) in the country, a cool climate and a rainy season varying from 8 to 9 months. These conditions are favorable for raising cattle, which explains why the Crete Congo Nil hosts $41 \%$ of the cattle population in Burundi (Epaphras et al. 2004).

A total of 144 Holstein crossbred cows, in their first stage of lactation or last month of pregnancy, were randomly sampled from 132 small farms located in eight villages of three administrative communes (Matana, Bururi and Songa). Of these, 73, 60 and 13 lactating cows were in their first, second and third parity respectively. As far as origin, 78 cows had been imported from Uganda, 65 cows had been born in Burundi and three had unidentified origin. Before genotyping, farmers were invited to estimate the probable percentage of EUT ancestry based on the conformation and milk production performance of their cows. They classified them into three groups, low $(<25 \%)$, medium $(25-75 \%)$ and high $(>75 \%)$ EUT ancestry.

\section{Phenotypes}

Dairy cows were hand milked and suckled twice a day, in the morning and evening. The quantity of milk suckled by calf was estimated by the weigh-suckle-weigh technique (Mandibaya et al. 2000), which was performed twice a week on 10 calves, in the morning and evening for a period of 5 months postpartum. The quantity of milk not suckled was measured with a calibrated cup once a month, in the week of the first Monday of the calendar month, on each cow and for a period of 10 months. DMY was calculated as the sum of milk suckled and collected by hand. Data were collected between April 2014 and January 2015, with a dry season from May to September 2014 and otherwise a rainy season. Average milk production per month is indicated for each animal in Table S1.

\section{Genotypes}

Nasal swabs were collected on each individual using the PG100 Performagen Livestock Kit, and DNA was extracted according to the protocol provided by DNA GENOTECK using the PG-AC4 Reagent Pack - Full Purification kit ${ }^{\circledR}$. The DNA concentration of all samples was verified by using a Qubit ${ }^{\circledR}$ 2.0 Fluorimeter (Invitrogen) with a Qubit ${ }^{\mathrm{TM}}$ dsDNA BR Assay, as recommended by Invitrogen, using $1.5 \mu \mathrm{l}$ of DNA volume. The DNA extracted was genotyped on an Illumina BovineSNP50 chip assay v2 ${ }^{\circledR}$ (Matukumalli et al. 2009) at the Labogena platform (Jouy-en-Josas, France).

Genotypes of cattle sampled in this study were combined with genotypes of 549 cattle belonging to 21 populations produced previously (Flori et al. 2009; Gautier et al. 2009, 2010; Matukumalli et al. 2009) and stored in the WIDDE database (Sempéré et al. 2015). These populations are representative of the main groups of cattle populations, i.e. EUT, West African taurine (AFT), Zebu cattle (ZEB) and admixed cattle. Details about all the populations considered are given in Table S2. Among the 49555 autosomal SNPs selected, we discarded SNPs that (i) were genotyped on less than $75 \%$ of the individuals in at least one breed, (ii) did not pass Hardy-Weinberg equilibrium tests following the procedure described by Kibwana et al. (2013) and (iii) displayed a minor allele frequency of less than 0.01. Individuals for which less than $95 \%$ of markers in their genomes were known were ignored.

\section{Analysis of population structure}

Unsupervised genotype-based hierarchical clustering was performed using the maximum likelihood method implemented in ADMIXTURE 1.04 (Alexander et al. 2009), and 
results were visualized with customized functions in the $\mathrm{R}$ environment.

\section{Analysis of farmers' judgement}

The Kappa test (Sim \& Wright 2005) was used to evaluate the concordance between rankings made by cattle keepers and results of DNA analysis, also grouped into low $(<25 \%)$, medium $(25-75 \%)$ and high $(>75 \%)$ percentage of EUT ancestry.

\section{Analysis of milk productivity}

A mixed linear model was chosen to estimate the effect of the percentage of EUT origin on DMY. This model assumes DMY is normally distributed, but this was not confirmed by visual inspection. A logarithmic transformation was the appropriate transformation to reach normality (PROC TRANSREG, SAS). Despite this, the model was applied to DMY without transformation because linear models are robust when normality of data is violated and because most scientific studies on milk production report results without transformation. The model included the fixed effects for the month in lactation (1-12), communes (Bururi, Matana or Songa), villages nested within communes (Nyavyamo or Rushemeza in Bururi; Gisarenda, Sakinyonga, Butwe or Mahango in Mantana; or Kinwa or Gahanda in Songa), parity (1-3 or more), season (rainy or dry season) and origin (imported or born in the country) as well as covariates for age at first calving (24-49 months) and for EUT admixture proportion (from $0.6 \%$ to $90.35 \%$ ), the random effects for the animal and the error terms. The different covariates are listed in Table S1 for each individual. In one approach, both random effects were assumed independently and normally distributed with null means and variances $\sigma^{2}$ and $v^{2}$ for the animal and residual terms respectively. All computations were done in SAS (PROC MIXED). For the second approach, the genomic relationship between animals was obtained from the SNP information, and computations were done with the BLUPF90 family of programs (Miztal et al. 2012). Significance levels were set at $1 \%$.

\section{Data availability}

Genotypes will be publicly available in the WIDDE repository (http://widde.toulouse.inra.fr/widde/), and phenotypes and covariates are detailed in Table S1.

\section{Results}

\section{Population structure}

To provide a fine-scale genetic characterization of cattle sampled in Burundi, we combined the SNP data obtained on 138 Ankole-Holstein crossbred and 36 pure Ankole individuals from this study with genotypes from 21 worldwide cattle populations representative of EUT, AFT, ZEB and admixed populations (Table S2). Thus, 42636 SNPs genotyped on 723 animals were analyzed. Performing an unsupervised hierarchical clustering of the individuals, with a number of three predefined clusters, we interpreted the clusters shown in green, blue and red (Fig. 1) as EUT, AFT and ZEB ancestry respectively (Gautier et al. 2010) and estimated the different ancestry proportions of individuals from Burundi (Table S3). For example, ANK individuals had on average $57 \pm 0.2 \%, 41 \pm 0.2 \%$ and $0.8 \pm 0.01 \%$ of ZEB, AFT and EUT ancestries respectively. On the other hand, ancestry proportions of crossbred populations were variable, with a predominance of EUT ancestry (Fig. 1). Overall, these proportions were $57 \pm 19 \%$ for EUT, $26 \pm 13 \%$ for ZEB and $17 \pm 6 \%$ for AFT ancestry. Almost $78 \%$ of the crossbred cows had between $25 \%$ and $75 \%$ EUT ancestry, and $16 \%$ had more than $75 \%$ EUT ancestry. No clear geographical substructure was observed.

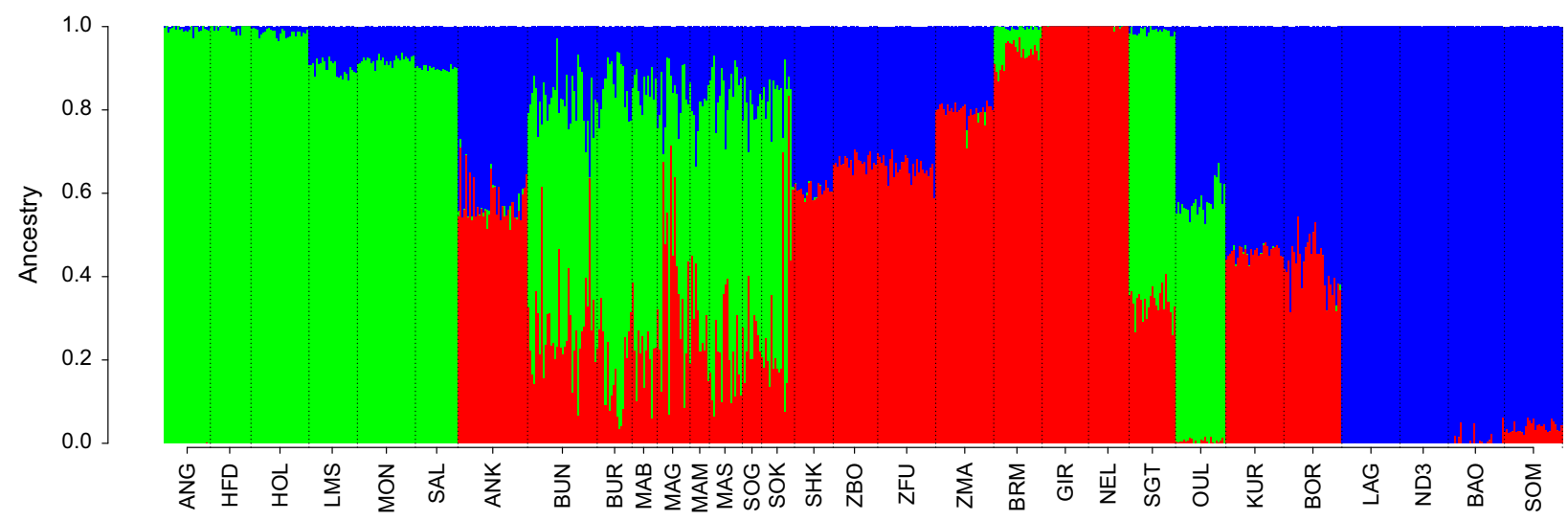

Figure 1 Unsupervised hierarchical clustering results of the 723 individuals genotyped on 42636 SNPs with an inferred number of clusters $K=3$. The proportions of each cluster ( $y$-axis) are represented for each individual. Proportions that are interpreted as representative of EUT, AFT and ZEB ancestries are plotted in green, blue and red respectively. 
We compared this accurate estimation of EUT ancestry with the farmers' estimations based on the conformation and milk production performance of their cows. A total of 141 cows were genotyped and scored by farmers (Table 1). The Kappa coefficient was very low $(\kappa=0.06)$ and not significantly different from null, suggesting agreement in rankings formulated by farmers and by DNA analysis was not better than by chance. Inversely to admixture proportions, farmers considered that $11 \%, 41 \%$ and $48 \%$ of their cows had low, medium and high proportion of EUT ancestry respectively.

\section{Milk productivity}

The mean ( \pm standard error) milk yield not suckled was $3.58 \pm 0.06 \mathrm{l} /$ day, ranging from 0.75 to $11.75 \mathrm{l} /$ day, and was $2.90 \pm 0.13,3.40 \pm 0.06$ and $4.71 \pm 0.21 \mathrm{l} /$ day for cows with low $(<25 \%)$, medium $(25-75 \%)$, and high $(>75 \%)$ proportion of EUT ancestry respectively. Average milk suckled was $2.04 \pm 0.47 \mathrm{l} /$ day during the first 5 months after parturition. This suggests that average total milk produced was $5.62 \mathrm{l} /$ day. Average age at first calving was $36.96 \pm 7.03$ months, with a range of 24-49 months, and similar for cows with low $(36.78 \pm 6.97)$, medium $(36.99 \pm 7.14)$ and high $(36.74 \pm 7.21)$ proportions of EUT ancestry.

For both modelling approaches (i.e. considering genomic relationships or not), month of lactation and EUT proportion were the only significant effects on DMY. Because they were similar between models, only least-square means from the model not considering genomic relationships are reported. Milk production was highest during the first 3 months of lactation and declined thereafter (Fig. 2). The DMY increased by $0.03 \pm 0.01 \mathrm{l} /$ day for each percentage increase in the proportion of EUT ancestry. For example, a crossbred cow with an average proportion of $57 \%$ EUT ancestry would be expected to produce $1.5 \mathrm{l}(=57 \times 0.03 \mathrm{l})$ more than a purebred Ankole. The variance associated with the animal effect represented $69 \%$ and $63 \%$ respectively of the total variation when genomic relations were or were not considered or not.

Although statistically not significant, differences were also observed between villages (Fig. 3) and origin. For example, cows in the village of Gisarenda had the highest mean DMY and the lowest mean EUT (46.33\%) proportion.

Table 1 Proportion of European taurine (\%) according to the rankings made by cattle keepers and the results of admixture analysis based on DNA genotyping: absolute number of responses.

\begin{tabular}{lccc}
\hline \multirow{2}{*}{$\begin{array}{l}\text { Ranking made by } \\
\text { cattle breeders (\%) }\end{array}$} & \multicolumn{3}{l}{ Results of admixture analysis } \\
\cline { 2 - 4 } \cline { 2 - 4 }$<25 \%$ & $25-75 \%$ & $>75 \%$ \\
\hline$<25$ & 4 & 5 & 0 \\
$25-75$ & 10 & 44 & 55 \\
$>75$ & 2 & 8 & 13 \\
\hline
\end{tabular}

Also, cows born in Burundi (mean EUT $=54.34 \%$ ) produced on average of $0.44 \mathrm{l} /$ day more milk than did imported cows ( mean EUT $=59.98 \%$ ).

\section{Discussion}

Crossbreeding with highly selected breeds is often implemented in developing countries to rapidly improve the productivity of local populations (Leroy et al. 2015), and Burundi is no exception. In this study, we characterized at the genome-wide level the genetic diversity of the Ankole cattle breed, sampled in Burundi, and confirmed its ZEB $\times$ AFT admixed origin, in agreement with previous reports on the genetic history of East African cattle (Hanotte et al. 2002). We also showed that crossbred animals considered in this study were EUT $\times$ AFT $\times$ ZEB admixed, as expected because they were obtained by crossing Ankole with EUT breeds such as Holstein.

Crossbred animals present a high proportion of EUT ancestry (i.e. $57 \%$ on average), suggesting that they may benefit from positive heterosis. As a matter of fact, we found a significant increase in milk collected by hand (i.e. not suckled) in those with higher EUT percentage: means were 2.90 and $4.71 \mathrm{l} /$ day for cows with low $(<25 \%)$ and high $(>75 \%)$ percentage of EUT ancestry respectively. These means are higher than the milk yield (not suckled) of pure Ankole cattle, for example, 2.1 l/day in Burundi (Hatungumukama et al. 2008), $2.2 \mathrm{l}$ /day in Uganda (Kugonza et al. 2011) and 2.4 l/day in R. D. Congo (Kibwana et al. 2012). The mean total milk produced (5.62 l/day suckled and not) was similar to that reported in Holstein crossbred cows kept under MCLS in other countries: 5.2 l/day in R.D. Congo (Kibwana et al. 2013), 5.2 l/day in Ethiopia (Tassew \& Seifu $2009)$ and $6.7 \pm 0.4 \mathrm{l} /$ day on the eastern coast of Tanzania (Bee et al. 2006).

This significant increase in milk productivity should improve family nutrition and provides extra income to MCLS farmers. In Burundi, the quantity of milk sold by most

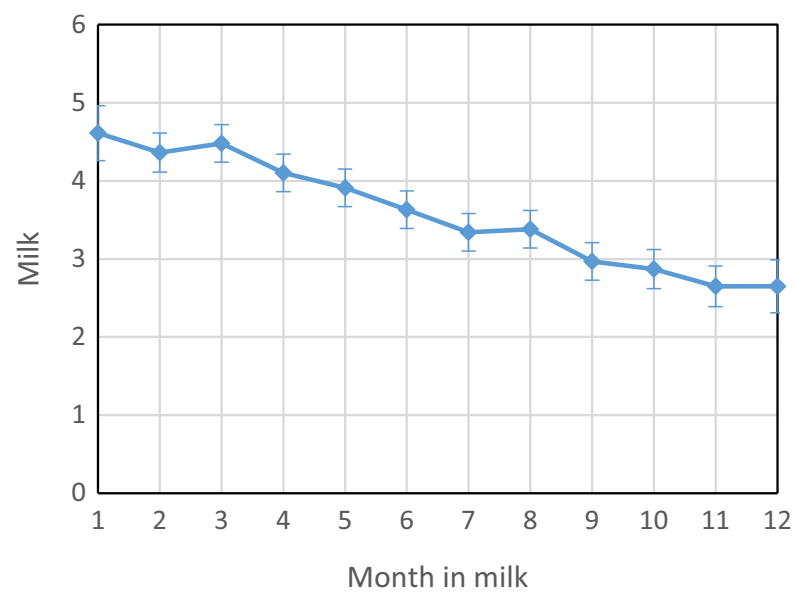

Figure 2 Milk least-squares means (I/day) per month in lactation. 

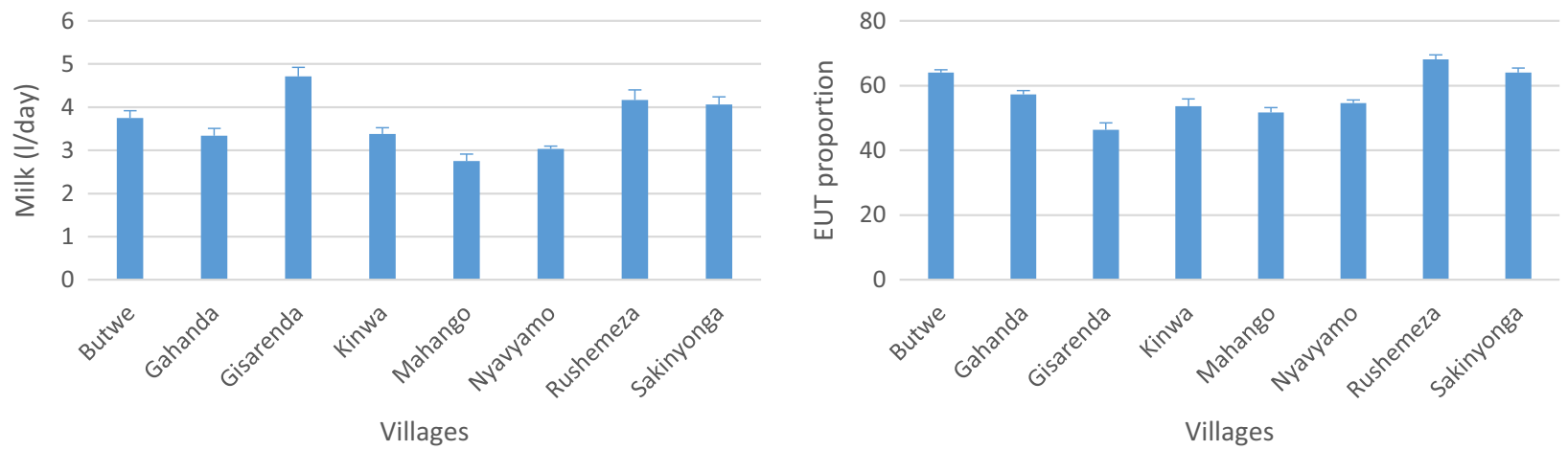

Figure 3 Milk least-squares means (I/day) and means of European (EUT) admixture proportion per village.

MCLS farmers varies from 30\% to 60\% of DMY depending on rural market access. Due to the breeders' small processing know-how, the lack of electricity and cold chain in rural areas, fresh daily milk produced in the morning is marketed, whereas the evening milk production (around 40\%) is usually consumed by the producer and/or given free to the neighbors and exchanged for forage.

However, in this study, the observed DMY increase was not as spectacular as expected. Indeed, according to a review of 23 studies, lactation milk yields of crossbred dairy cows with 50 percent Bos taurus can be two to three times higher than that of local cattle (Galukande et al. 2013). Here, without information on milk produced by cows with $0 \%$ EUT, we observed milk yield of cows with more than $75 \%$ EUT ancestry to be only $1.6(4.71 / 2.90)$ times higher than that of cattle with less than 25\% EUT ancestry. Such disappointing improvement could be partly attributed to inadequate management and feed resources in line with the requirements of these crossbred dairy cows. Indeed, advantages of crossbreeding are justifiable only if crossbred animals are raised in an adequate environment such that they can fully express their genetic potential (Leroy et al. 2015). The basic diet in MCLS includes Trypsacum laxum and Napier grass, with no legumes or concentrates. This diet, although not analyzed here, is not balanced to fill the gaps between available resources and animal needs for protein and minerals. Therefore, feed quality and quantity should be improved to supply the needs of crossbred animals, but the question of how MCLS breeders will pay for increased feed and how they will acquire the necessary knowledge must be addressed in future studies. Indeed, in many circumstances, production systems cannot be easily changed and adapted to fit the needs of crossbred animals (Leroy et al. 2015).

It is also possible that some alleles associated with high milk yield were not fully transferred from EUT breeds or selected for in crossbreds in local farms. For example, breeders may have favored crossbred animals with higher survivability instead of those with a higher ability to produce milk yield, but information on the length of productive lives and other components of cattle productivity was not available in this study. It would be interesting to investigate the genomic features underlying the effects of crossbreeding with a view of the entire genome and to determine whether haplotypes of the few influential bulls selected in Western countries for economic traits are found in crossbred animals. Note also that the choice of EUT breeds used to improve local breeds could be more profitable if it were possible to distinguish between progenitors whose offspring would show higher heterosis. One approach to doing so would be to identify QTL involved in heterosis formation and to follow the general theoretical framework proposed by Melchinger et al. (2007) for determining the contributions of the different types of genetic effects to heterosis. Reciprocally, use of genes hidden in low-yielding Ankole in EUT breeds could be a novel option for enrichment of genetic diversity for productivity traits in exotic cattle (Mwai et al. 2015).

A final explanation for the less than expected contribution of the EUT ancestry in milk yield improvement is methodological: the model proposed here includes a random animal effect $(a)$ and a fixed effect of the EUT admixture proportion $(t)$. Then, non-additive genetic effects may be confounded with direct additive effects, and this may explain the upward bias in the heritability estimates. It is also possible the random animal effect includes not only genetic background for milk yield but also for other traits including tolerance to disease (Detilleux 2012), which may also bias heritability estimates. The model was also constrained because sample size was limited and because no pedigree information was available, both of which are very important for the prediction of genetic parameters.

The lack of pedigree records may also explain why rankings of EUT ancestry formulated by MCLS breeders were not in agreement with results of DNA analysis $(\kappa=0.06)$. Indeed, due to the intense distribution of cows coming from Uganda with Burundi restocking, it remains difficult for most beneficiaries to estimate percentage of EUT ancestry based only on phenotypic observations. Moreover, hard conditions characterized mainly by small farmers' low 
capacity to feed animal cause the farmers to be confused about their cows' genotypes and their adaptability to local conditions. Even if Burundian breeders would like to increase milk productivity by crossbreeding Ankole with EUT, they are still limited by low availability of land, which allows the majority of them to rear only a maximum of three adult cows. Moreover, there remains a need for providing proper guidelines for management and care of crossbred animals. In addition, such programs will need to be strengthened by an adequate program of milk value chain with milk collecting, processing and marketing being well studied (Leroy et al. 2015). Otherwise, there is the risk that interest in the crossbreeding program will decrease and will possibly generate little gain in the productivity of crossbred cows. Research about such situations was funded by socio-economic studies that showed that disinterest was linked with the disappearance of crossbred cows within farms (Roschinsky et al. 2015).

Although data from this study are too limited for farreaching conclusions on the use of crossbreeding with EUT breeds in Burundi, genetic improvement of Ankole cattle could be considered by MCLS breeders and decision-makers as an alternative. Indeed, milk productivity could gradually be raised by selective breeding because milk heritability in crossbreds raised in Burundi (Mahwa station) was shown to be close to $27 \%$ (Hatungumukama \& Detilleux 2009). The genetic gain associated with the selection of the top 5\% of the cows will be close to $0.34 \mathrm{l}$ of milk per year [calculated as $\left.\left(h^{2} \times i \times \sigma_{\mathrm{p}}\right) / L=(0.027 \times 2.06 \times \sqrt{3.43}) / 2.8\right]$.

Specific labeling of purebred Ankole products could, in addition to the promotion of the use of the Ankole breed, allow breeders to benefit from higher prices for their products (e.g. Lauvie et al. 2008). Although selective breeding is comparatively slower than crossbreeding to generate highly productive cattle, it is more sustainable. But, to be successful, performance and pedigree records must be made available via recording systems adapted to the tropics, (i.e. contracted herds, bi-monthly or AM-PM recordings).

From a strict conservation point-of-view, selective breeding of Ankole cattle should guarantee better diversity across local breeds. Moreover, Ankole cattle could constitute a genetic source for better adaptation of EUT cattle to future extreme weather conditions because it can survive in extremely harsh and dry conditions. For example, animals with the lowest EUT ancestry could be used as a nucleus for recovery of the native genetic background in the current admixed population in Burundi, because it is widely recognized that on-farm management of genetic resources is the preferred method of conservation (Gibson et al. 2006). However, breeders do not consider the preservation of genetic resources per se but, instead, take into account genetic considerations and local development goals. Therefore, selective breeding of local cattle should be organized at the community level (e.g. Community Based Organization for Genetic Improvement of livestock), and the whole Ankole value chain should be analyzed with, for example, structure-conduct-performance models (Bett et al. 2012) to guarantee economic, social and environmental interest and to gain acceptance by all stakeholders along the value chain.

\section{Acknowledgements}

The authors thank the community team in animal health and farmers for their help in data collection. Jean Luc Guerin and Ngomirakiza Grégoire are also acknowledged for their participation to the current study. We thank Labogena (www.labogena.fr/) for the SNP genotyping. This work was supported by the Food Agriculture Organization (FAO).

\section{References}

Alexander D.H., Novembre J. \& Lange K. (2009) Fast model-based estimation of ancestry in unrelated individuals. Genome Research 19, 1655-64.

Bee J.K.A., Msanga Y.N. \& Kavana P.Y. (2006) Lactation yield of crossbred dairy cattle under farmer management in Eastern coast of Tanzania. Livestock Research for Rural Development 18, 2.

Bett H., Peters R.C., Kahi K.J. \& Bokelmann A.K. (2012) Linking utilisation and conservation of indigenous chicken genetic resources to value chains. Journal of Animal Production Advances 2, 33-51.

Detilleux J. (2012) A mathematical model to study resistance and tolerance to infection at the animal and population levels: application to E. coli mastitis. Frontiers in Genetics, 3, 146.

Epaphras A., Karimuribo E.D. \& Msellem S.N. (2004) Effect of season and parity on lactation of crossbred Ayrshire cows reared under coastal tropical climate in Tanzania. Livestock Research for Rural Development 16, Article \#42.

Flori L., Fritz S., Jaffrézic F., Boussaha M., Gut I. \& Heath S. (2009) The genome response to artificial selection: a case study in dairy cattle. PLoS One 4, e6595.

Galukande E., Mulindwa H., Wurzinger M., Roschinsky R., Mwai A.O. \& Sölkner J. (2013) Cross-breeding cattle for milk production in the tropics: achievements, challenges and opportunities. Animal Genetic Research 52, 111-25.

Gautier M., Flori L., Riebler A., Jaffrézic F., Laloé D., Gut I. \& Foulley J.L. (2009) A whole genome Bayesian scan for adaptive genetic divergence in West African cattle. BMC Genomics 10, 550.

Gautier M., Laloe D. \& Moazami-Goudarzi K. (2010) Insights into the genetic history of French cattle from dense SNP data on 47 worldwide breeds. PLoS One 5, e13038.

Gibson J., Gamage S., Hanotte O., Iñiguez L., Maillard J.C., Rischkowsky B. \& Toll J. (2006) Options and Strategies for the Conservation of Farm Animal Genetic Resources: Report of an International Workshop. Montpellier, France, 7-10 November 2005. CGIAR System-wide Genetic Resources Programme (SGRP)/Bioversity International, Rome, Italy.

Hanotte O., Bradley D.G., Ochieng J.W., Verjee Y., Hill E.W. \& Rege J.E. (2002) African pastoralism: genetic imprints of origins and migrations. Science 296, 336-9. 
Hatungumukama G. \& Detilleux J. (2009) Estimation of genetic and crossbreeding parameters for daily milk yield of Ayrshire $\times$ Sahiwal $\times$ Ankole crossbred cows in Burundi. Livestock Science 122, 359-62.

Hatungumukama G., Leroy P. \& Detilleux J. (2008) Non genetic effects on daily milk yield of Friesian cows in the Mahwa station (South Burundi). Revue d'Elevage et de Médecine Vétérinaire des Pays Tropicaux 61, 45-9.

Kibwana D.K., Makumyaviri A.M. \& Hornick J.L. (2012) Pratiques d'élevage extensif et performances de bovins de race locale et croisés des races laitières exotiques à Beni, RD Congo. Revue d'Elevage et de Médecine Vétérinaire des Pays Tropicaux 65, 67-74.

Kibwana D.K., Makumyaviri A.M. \& Hornick J.L. (2013) Effect of improved feeding and housing, Friesian blood level and parity on milk production of Ankole $\times$ Friesian cows. Pakistan Veterinary Journal 35, 76-80.

Kugonza D.R., Nabasirye M., Mpairwe D., Hanotte O. \& Okeyo A.M. (2011) Productivity and morphology of Ankole cattle in three livestock production systems in Uganda. Animal Genetics Research $48,13-22$.

Lauvie A., Danchin-Burge C., Audiot A., Brives H., Casabianca D.F. \& Verrier E.A. (2008) Controversy about crossbreeding in a conservation programme: the case study of the Flemish Red cattle breed. Livestock Science 118, 113-22.

Leroy G., Baumung R., Boettcher P., Scherf B. \& Hoffmann I. (2015) Review: sustainability of crossbreeding in developing countries; definitely not like crossing a meadow. Animal 10, 26273.

Mandibaya W., Mutisi C., Hamudikuwanda H. \& Titterton M. (2000) The quantity and composition of milk taken by calves reared by restricted suckling in smallholder dairy farming areas of Zimbabwe. Livestock Research for Rural Development 12, 1-10.

Matukumalli L.K., Lawley C.T., Schnabel R.D., Taylor J.F., Allan M.F., Heaton M.P. \& Van Tassell C.P. (2009) Development and characterization of a high density SNP genotyping assay for cattle. PLOS ONE, 4, e5350.

Melchinger A.E., Piepho H.P., Utz H.F., Muminovic J., Wegenast T., Tötjék O., Altmann T. \& Kusterer B. (2007) Genetic basis for heterosis growth-related traits in Arabidopsis investigated by testcross progenies of near-isogenic lines reveals a significant role of epistasis. Genomics 177, 1827-37.

Miztal I., Tsuruta S., Aguilar I. \& Legarra A. (2012) Adaptation of BLUPF90 package for genomic computation. Proceedings of the 63rd Annual meeting of the European Association of Animal Production (EAAP), 27-31 August, Bratislava, Slovakia.
Mwai O., Hanotte O., Kwon Y.J. \& Cho S. (2015) African indigenous cattle: unique genetic resources in a rapidly changing world. Asian-Australian Journal of Animal Science 28, 91121.

Roschinsky R., Kluszczynska M., Sölkner J., Puskur R. \& Wurzinger M. (2015) Smallholder experiences with dairy cattle crossbreeding in the tropics: from introduction to impact. Animal 9, 150-1.

Sempéré G., Moazami-Goudarzi K., Eggen A., Laloë D., Gautier M. \& Flori L. (2015) WIDDE: a web-interfaced next generation database for genetic diversity exploration, with a first application in cattle. BMC Genomics 16, 940.

Sim J. \& Wright C.C. (2005) The kappa statistic in reliability studies: use, interpretation and sample size requirements. Physical Therapy $85,257-68$.

Tadesse M. \& Dessie T. (2003) Milk production performance of Zebu, Holstein Friesian and their crosses in Ethiopia. Livestock Research for Rural Development 15, 1-9.

Tassew A. \& Seifu E. (2009) Smallholder dairy production system and emergency of dairy cooperatives in Bahir dar Zuria and Mecha Woredas, Northwestern Ethiopia. World Journal of Dairy \& Food Science 4, 185-92.

Weindl I., Lotze-Campen H., Popp A., Müller C., Havlík P., Herrero M., Christoph Schmitz C. \& Rolinski S. (2015) Livestock in a changing climate: production system transitions as an adaptation strategy for agriculture. Environmental Research Letters 10, 094021.

Wurzinger M., Ndumu D., Baumung R., Drucker A., Okeyo A.M., Semambo D.K., Byamungu N. \& Sölkner J. (2006) Comparison of production systems and selection criteria of Ankole cattle by breeders in Burundi, Rwanda, Tanzania and Uganda. Tropical Animal Health and Production 38, 571-81.

\section{Supporting information}

Additional supporting information may be found online in the supporting information tab for this article:

Table S1 Phenotypic data and covariates.

Table S2 Description of cattle populations.

Table S3 Proportion of cluster 1, 2 and 3, interpreted as representative of ZEB, EUT and AFT ancestries, respectively, estimated for each individual belonging to cattle populations from Burundi (i.e. ANK, BUN, BUR, MAB, MAG, MAM, MAS, SOG and SOK). 